Article

\title{
Analysis of Flow Characteristics and Pressure Drop for an Impinging Plate Fin Heat Sink with Elliptic Bottom Profiles
}

\author{
Zhipeng Duan *, Xianghui Lv, Hao Ma *®D, Liangbin Su@ and Mengqiao Zhang \\ School of Mechanical, Electronic and Control Engineering, Beijing Jiaotong University, Beijing 100044, China; \\ 18125982@bjtu.edu.cn (X.L.); 16116368@bjtu.edu.cn (L.S.); 17222026@bjtu.edu.cn (M.Z.) \\ * Correspondence: zpduan@bjtu.edu.cn (Z.D.); 18116018@bjtu.edu.cn (H.M.)
}

Received: 8 December 2019; Accepted: 24 December 2019; Published: 27 December 2019

\begin{abstract}
The performance of impingement air cooled plate fin heat sinks differs significantly from that of parallel flow plate fin heat sinks. The impinging flow situations at the entrance and the right-angled bends of the plate fin heat sink are quite involved. Flow characteristics of a plate fin heat sink with elliptic bottom profiles cooled by a rectangular impinging jet with different inlet widths are studied by numerical simulations. The results of pressure drop of numerical simulations and experimental results match quite well. The numerical results show that at the same flow rate, the pressure drop decreases with the increase of the impingement inlet width, and the pressure drop increases significantly with the increase of the fin height. The larger the impingement inlet width of air-cooled plate fin heat sink, the milder the pressure drop changes with velocity. Pressure drop for an impinging plate fin heat sink without elliptic bottom profiles is larger than that with elliptic bottom profiles at the same inlet width and velocity. Based on the fundamental developing laminar continuum flow theory, an improved model which is very concise and nice for quick real world approximations is proposed. Furthermore, this paper verifies the effectiveness of this simple impinging pressure drop model.
\end{abstract}

Keywords: plate fin heat sink; pressure drop; impingement; elliptic bottom profiles; model

\section{Introduction}

As the function of modern computers advances, the dissipating heat in electronic environment is increasing with power flux. Simultaneously, thermal dissipation in the electronic equipment is significantly difficult because of high heat load. The cooling method with impinging flow for heat sinks is interest of researchers for solving these problems.

If one treats fins as a hot fluid, the fins and flow paths of heat sink could be considered as a type of heat transfer. The heat performance of a heat sink depends significantly on the flow-stream direction. Three fundamental one-dimensional flow forms of heat interchangers including counter-flow, cross-flow, and parallel-flow are widely used. Counter-flow has better potential to accomplish high heat removal. The thermal performance of impinged flow may precede that of cross flow since the flow type for a heat sink with impinging flow is in-between the counter-flow and cross-flow. So it has a better cooling capacity for impinging flow than for parallel flow because of its high cooling effectiveness [1].

Numerical studies were conducted by Biber [2] to estimate a single isothermal channel pressure drop of impinging flow with variable inlet widths. Biber numerically developed the correlation for pressure drop coefficient of heat sinks with different heat sink parameters in this work. However, the correlation was not validated experimentally. Duan and Muzychka [3] studied the pressure drop of an 
impinging air cooled plate fin heat sink and presented a simple model and conducted experiments to validate the approximated effectiveness of the model. Ma et al. [4] numerically investigated the flow characteristics and made entropy generation analysis of $\mathrm{Al}_{2} \mathrm{O}_{3}$-water nanofluid in microchannel plate fin heat sinks. Ma et al. [5] numerically investigated flow characteristics in hydrodynamic entrance region of rectangular microchannels with lattice Boltzmann method. Kim et al. [6] studied the jet impingement thermal performance of plate fin and pin fin heat sinks through experiments and numeric analysis, and built a model with volume average method to investigate the pressure drop and thermal performance. They found that optimized pin fin heat sinks demonstrated relatively better thermal performance for low pumping power. Yang et al. [7] investigated the turbulent flow and thermal transfer characteristics for the rotating and stationary pin-fin heat sinks subjected to impinging air flow by means of numerical solutions. The effects of fillet profiles setting at the bottom of channels on fluid flow and heat performance of an impinging flow plate fin heat sink were investigated numerically by Wong and Indran [8]. Do et al. [9] proposed an improved solution to investigate the distributions of velocity and temperature of a parallel-flow plate heat sink with uniform impingement. Ndao et al. [10] experimentally investigated the influences of cross flow area and pin fin shapes on the single-phase impingement point heat transfer coefficients for micro pin fins. Tang et al. [11] made numerical simulations to analyze heat transfer characteristics of jet impingement with a novel single cone heat sink. It is found that the heat transfer capability of a cone heat sink with fluid impingement is better than that of a conventional plate fin heat sink. In order to analyze the effect of fin shapes on the heat sink property, Li et al. [12] investigated the distributions of the flow fields and temperature fields of heat sinks with short plate fins subjected to impinging flow. The pressure drop for three sets of fin shapes including rectangular, round-headed, and elliptic were studied in this paper. They found that the fin shapes have prominent influence on the secondary flow as well as flow separation. Li et al. [13] experimentally and numerically investigated the thermal performance of plate fin heat sink subjected to impinging air flow with variable Reynolds numbers, the impinging distance, and the fin constructions. Khattak and Ali [14] made a critical review to summarize the development of air-cooled heat sink with forced flow arrangement. Chang et al. [15] investigated the air cooling module of electronic equipment and found the influences of heat load of heater and input current to cooler by experiments. Wang et al. [16] investigated the performance of a thermoelectric generator which has air cooling system and made two-stage optimized design. Saraireh [17] made the three-dimensional computational fluid dynamics (CFD) simulation of fluid flow and heat transfer capabilities for the plate fin and pin fin heat sinks with different inlet velocities. Hussain et al. [18] developed a CFD model to compare the flow and thermal characteristics for the plate fin heat sink of fillet profiles in parallel flow arrangement with that of a rectangular channel without fillet profiles in impinging flow. Feng et al. [19] made numerical simulations to investigate the thermal and flow performance of heat sinks which possess finned metal foam subjected to impinging air flow with different configuration parameters. Hadad et al. [20] developed a V-groove cool-plate to investigate its pressure drop and thermal performance and made a structural optimization. They studied the effect of tilt angle on flow and thermal performance simultaneously. Kaloudis et al. [21] used the standard k- $\varepsilon$ model to make numerical simulations and found the conjugate heat transfer effects in a computer chassis. Fully and partially shrouded heat sinks with forced convection flow were used by Prstic et al. [22] to numerically and experimentally study the influence on thermal performance, and they found that the pressure drop with partially shrouded heat sinks decreased $50 \%$ compared with fully shrouded heat sinks. Mesalhy et al. [23] experimentally and numerically studied the hydrodynamic and heat transfer characteristics for a plate fin heat sink with a variable rectangular impinging jet. Chen et al. [24] made numerical simulations to investigate the performance of the thermoelectric generator system and optimized the operation by Taguchi method. Rezania and Rosendahl [25] compared the cooling performance of micro-structured flat-plate heat sinks with that of cross-cut heat sinks in thermoelectric generation application. Leng et al. [26] developed a three-dimensional solid-fluid model to complete the optimization of thermal performance and bottom wall temperature uniformity for double-layered 
heat sink with the method of simplified conjugate gradient. Naphon et al. [27] investigated the flow performance of micro-channel heat sink with impinging nanofluids flow employing experiments and numerical simulations. Huang and Chen [28] made numerical simulations on account of optimal design problems for non-uniform fin heights and widths applied in the impinging heat sink module. Chen et al. [29] made numerical simulations to investigate the flow and thermal performance for the impingement/effusion double-wall heat exchanger with different cooling crossflow arrangements including zero, maximum, blocked maximum crossflow. They found that the blocked maximum crossflow displays relatively better cooling performance for the Reynolds numbers of 1000 compared to zero crossflow. Liang et al. [30] carried out a novel optimal design of an air-to-air heat exchanger with cross-corrugated triangular ducts employing particle swarm optimization algorithm, considering the Colburn factor, friction factor, and comprehensive thermal hydraulic performance index as the objective functions. Ling et al. [31] investigated the flow characteristics of non-Newtonian nanofluids flow in shell side of helical baffled heat transfer combined with elliptic tubes. They pointed out that a remarkable heat transfer enhancement can be obtained. Thermal shock was used by Chang et al. [32] to inhibit biofilm formation in the treated sewage source heat pump system.

As a cooling method with promising development prospects, impinging jet cooling will be more widely used to solve cooling problems in various fields. Most of the researches carried out for impinging air cooling were concentrated on the effect of the heat sink geometry. The goal of this paper is to study the pressure drop distribution of a plate fin heat sink based on impinging flow with different inlet widths, fin heights, flow velocities, and channel shapes and verify the effectiveness of this improved concise pressure drop model.

For engineering applications, it is convenient to employ a general simple pressure drop model to predict pressure drop of fluid flow in impinging plate fin heat sinks. This proposed model should be preferable because the difficulty and investment are negligible compared with the cost of alternative methods such as CFD simulations or other approaches. CFD simulations, molecular dynamic simulations, or lattice Boltzmann equation method require great computational effort, which is not justified in practical and engineering calculations. The developed models are useful for the practical engineering design of microchannel plate fin heat sinks because they indicate the effects of various independent parameters such as the inlet width, fin height, flow velocity, and the effective lengths of these two orthogonal channels. When the inlet width, fin height, flow velocity, and the effective lengths of these two orthogonal channels are known, the pressure drop can be expediently obtained using commercially available algebraic software tools such as Maple or Matlab.

\section{Materials and Methods}

To the best knowledge of the authors, the investigations for the effects of adding elliptic bottom profiles (fillet profiles) to a plate fin heat sink are scarce. The objective of this study is to investigate the flow characteristics of a plate fin heat sink with elliptic bottom profiles subjected to impinging air flow. The fillet profile is shaped as semiellipt which has the major semiaxis and minor semiaxis of $1.5 \mathrm{~mm}$ and $1.125 \mathrm{~mm}$, respectively. Simulations are carried out by the software Fluent. The model is developed for the low Reynolds number laminar flow in the inter-fin channels of impingement flow plate fin heat sinks as shown in Figure 1. The computational unit of the number 5 plate fin heat sink is shown in Figure 1b, with a fillet profile on the bottom of the channel, which is different from other traditional heat sinks. In this study, five different inlet widths are considered including $10 \% L$, $25 \% L, 50 \% L, 75 \% L$, and $100 \% L$. The air enters in the middle top then exits from the sides (TISE). Biskeborn et al. [33] made an experiment to report the flow characteristics for unique "serpentine" squared pin fins with TISE arrangement. Hilbert [34] developed an original laminar flow heat sink model which uses two kinds of fin shapes including triangular and trapezoidal on the inclined planes of the base. In this paper, we choose five kinds of plate fin heat sinks subjected to impinging flow, which are different from each other in geometry. The geometry parameters of the plate fin heat sink is 
shown in Table 1. According to the table, the plate fin heat sink of \#1 and \#2 are same in geometrical parameters except the height.

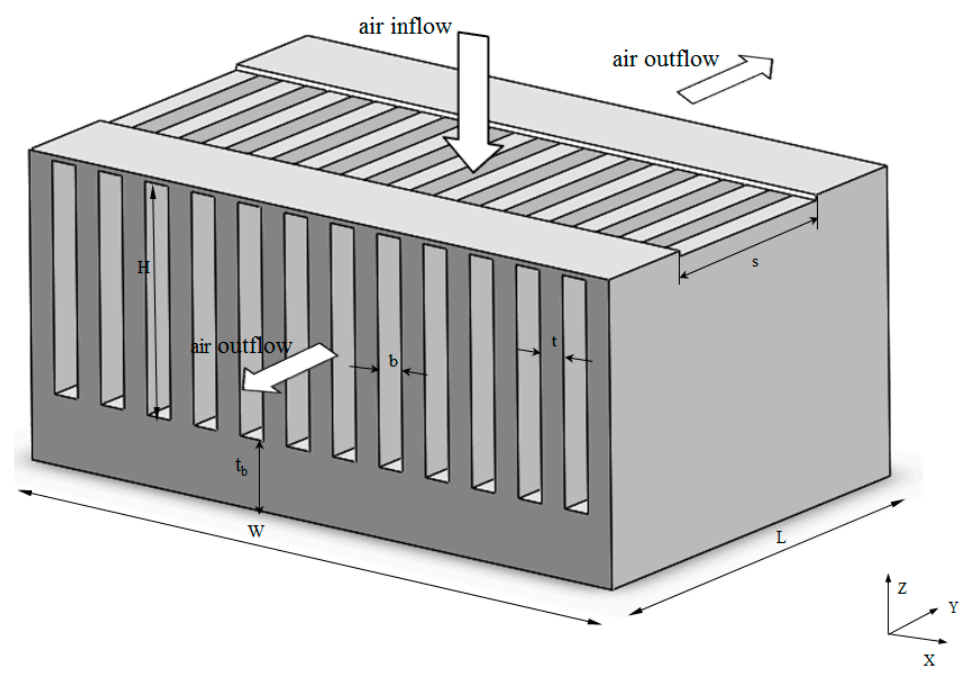

(a)

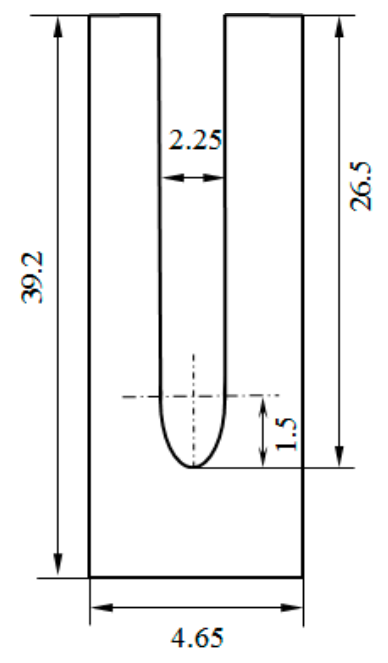

(b)

Figure 1. The physical model of the plate fin heat sink. (a) Schematic diagram of a plate fin heat sink, (b) computational unit of \#5 plate fin heat sink.

Table 1. Geometry parameters of the plate fin heat sinks.

\begin{tabular}{cccccc}
\hline Dimension & $\mathbf{\# ~ \mathbf { ~ }}$ & $\mathbf{\# ~ 2}$ & $\mathbf{\# ~ 3}$ & $\mathbf{\# ~ 4}$ & \# 5 (with Elliptic Bottom Profiles) \\
\hline$L(\mathrm{~mm})$ & 127 & 127 & 127 & 127 & 127 \\
$W(\mathrm{~mm})$ & 122 & 122 & 116 & 116 & 122 \\
$t_{b}(\mathrm{~mm})$ & 12.7 & 12.7 & 12.7 & 12.7 & 12.7 \\
$t(\mathrm{~mm})$ & 1.2 & 1.2 & 1.2 & 1.2 & 1.2 \\
$b(\mathrm{~mm})$ & 2.25 & 2.25 & 4.27 & 4.27 & 2.25 \\
$H(\mathrm{~mm})$ & 26.5 & 50.0 & 34.0 & 50.0 & 26.5 \\
$N_{f}$ & 36 & 36 & 22 & 22 & 36 \\
\hline
\end{tabular}

One dimensional pressure drop model of plate fin heat sink subjected to impinging flow is developed as follows. We choose one channel as computational domain and only investigated half of the heat sink because of the symmetry for flow and pressure distributions of the other half. This approach can lead to considerable simplification, especially when the original problem requires a great deal of time and computational steps. Then we obtain the simplified model as shown in Figure 2. $L_{e f f 1}$ and $L_{\text {eff } 2}$ represent the effective lengths of these two orthogonal channels. This shape of the streamline length can be considered as a right-angled path with orthogonal height of $0.5 \mathrm{H}$ and orthogonal length of $(0.5 L-0.25 \mathrm{~s})$. The flow situation at the entrance of the plate fin heat sink is very involved, as well as the right-angled bends. 


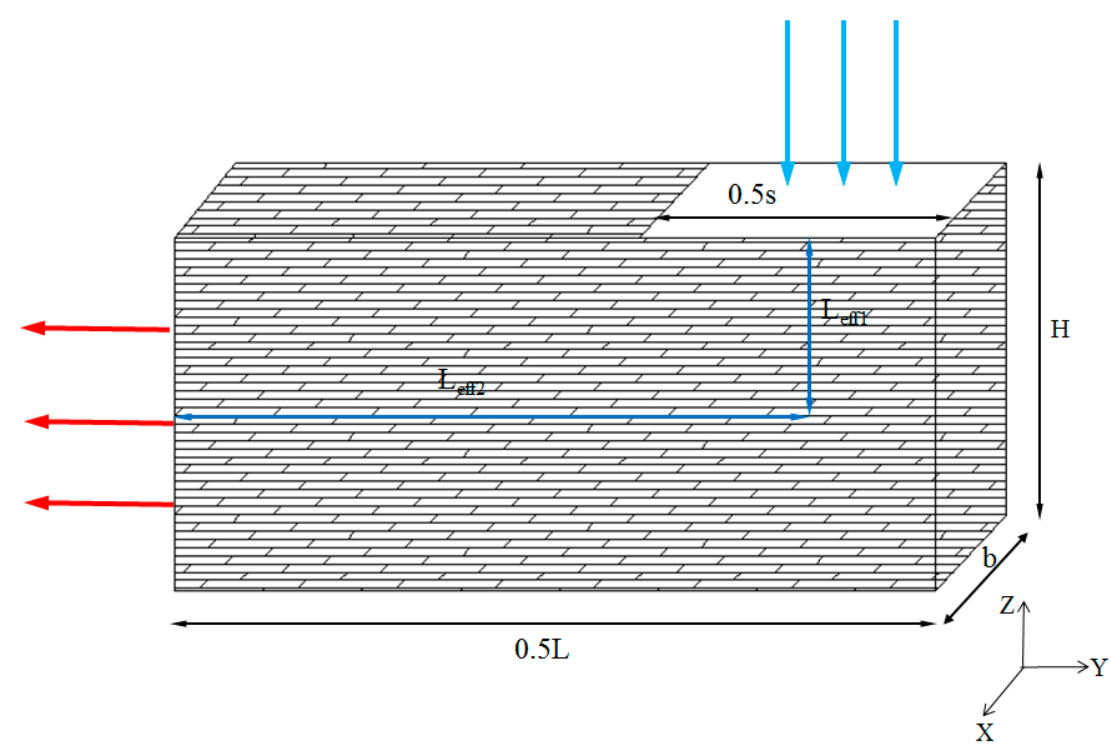

Figure 2. The simplified model.

Three fundamental assumptions are made in the process of numerical simulations for the pressure drop of plate fin heat sink subjected to impinging flow:

(1) Steady incompressible flow;

(2) Negligible buoyancy, viscous heating;

(3) Constant fluid properties.

The continuity equation, momentum equations are shown as follows

$$
\begin{gathered}
\frac{\partial u}{\partial x}+\frac{\partial v}{\partial y}+\frac{\partial w}{\partial z}=0 \\
u \frac{\partial u}{\partial x}+v \frac{\partial u}{\partial y}+w \frac{\partial u}{\partial z}=-\frac{1}{\rho} \frac{\partial p}{\partial x}+\frac{\mu}{\rho} \nabla^{2} u \\
u \frac{\partial v}{\partial x}+v \frac{\partial v}{\partial y}+w \frac{\partial v}{\partial z}=-\frac{1}{\rho} \frac{\partial p}{\partial y}+\frac{\mu}{\rho} \nabla^{2} v \\
u \frac{\partial w}{\partial x}+v \frac{\partial w}{\partial y}+w \frac{\partial w}{\partial z}=-\frac{1}{\rho} \frac{\partial p}{\partial z}+\frac{\mu}{\rho} \nabla^{2} w
\end{gathered}
$$

Since the measurement of local pressure along the flow is difficult in microchannels, the measurement of the pressure drop across the inlet and outlet manifolds is only conducted. The resulting pressure drop measurement represents the combined effect of the losses in the bends, entrance and exit losses, developing region effects, and core frictional losses. The pressure drop data are affected by microscale, which should not come as a surprise since values for the macroscale have been obtained empirically from measurements. According to Bernoulli's equation, the pressure drop model expression is written considering both the frictional and dynamic losses.

$$
\Delta P=\left[\left(K_{c}+K_{\text {ort }}+4 f_{a p p 1} \frac{L_{e f f 1}}{D_{h_{1}}}\right) \frac{4 H^{2}}{s^{2}}+4 f_{a p p 2} \frac{L_{e f f 2}}{D_{h_{2}}}+K_{e}\right] \frac{1}{2} \rho V_{c h_{2}}{ }^{2}
$$

Duan and Muzychka proved that in the neighborhood of circular and parallel plate channels $\left(x^{+} \leq 0.001\right)$ inlets, $f_{a p p} R e$ is almost independent of channel shape. Duan et al. [35] made numerical simulations of pressure drop for three-dimensional rectangular microchannels. Duan and He [36] demonstrated that a relationship between the rate of the dimensionless mean wall shear stress reduction and the rate of the dimensionless mean wall heat flux reduction might exist. Duan et al. [37] 
demonstrated that the appropriate drag coefficient could be related to the Nusselt number. The boundary layer performance in the position of channel entrance is generally identical to that in a thin plate. It clarifies the reason that $f_{a p p} R e$ is almost independent of channel shape in the neighborhood of the inlet. The influences of geometry characters become more prominent with the boundary layer developing in downstream $\left(x^{+}>0.001\right)$. The accessorial pressure defect $\Phi\left(x^{+}\right)$in a rectangular channel can be calculated with a model developed by Duan and Muzychka [38,39] in terms of developing laminar regime:

$$
\begin{gathered}
f_{a p p} R e_{D_{h}}=\frac{24}{\left(1+\left(\frac{b}{H}\right)\right)^{2}\left\{1-\frac{192\left(\frac{b}{H}\right)}{\pi^{5}}\left[\tanh \left(\frac{\pi}{2\left(\frac{b}{H}\right)}\right)+\frac{1}{243} \tanh \left(\frac{3 \pi}{2\left(\frac{b}{H}\right)}\right)\right]\right\}}+\Phi\left(x^{+}\right) \\
\Phi\left(x^{+}\right)=\frac{1}{3 x^{+}\left(1+8 K n^{*}\right)^{2}}-2 \sum_{i=1}^{\infty} \frac{\left(3-\exp \left(-4 \alpha_{i}^{2} x^{+}\right)\right) \exp \left(-4 \alpha_{i}^{2} x^{+}\right)}{\alpha_{i} x^{+}\left(1+8 K n^{*}+4\left(\alpha_{i} K n^{*}\right)^{2}\right)} \\
x^{+}=\frac{L}{D_{h} \operatorname{Re}_{D_{h}}}
\end{gathered}
$$

The friction factor and Reynolds number product of rectangular ducts short asymptote for slip flow is almost independent of the duct shape and therefore can be used to calculate by Equation (7). In order to predict the pressure loss of plate fin heat sinks, an asymptotic limit method is employed here. The eigenvalue $\alpha_{i}$ is suitable for this equation

$$
\alpha_{i} J_{0}\left(\alpha_{i}\right)-2\left(1+\mathrm{Kn}^{*} \alpha_{i}^{2}\right) J_{1}\left(\alpha_{i}\right)=0
$$

The first kind of order $v$ Bessel function is expressed by $J_{v}(\mathrm{x})$. Only the first two items in the infinite series are really contributed, which are applied in practical engineering limit of $x^{+} \geq$ 0.01 . It is concluded that Equation (6) absolutely properly approaches the $x^{+} \rightarrow 0$ asymptote $2 / \mathrm{Kn}^{*}$. Consequently, the complicated form can be simplified as Equation (10) without ignoring accuracy too much in the calculation of the friction factor and Reynolds number product for practical engineering applications. It can also be demonstrated that Equation (6) reduces to its continuum flow limits as $K n^{*} \rightarrow 0$ :

$$
\begin{aligned}
f_{a p p} R e_{D_{h}}= & \frac{24}{\left(1+\left(\frac{b}{H}\right)\right)^{2}\left\{1-\frac{192\left(\frac{b}{H}\right)}{\pi^{5}}\left[\tanh \left(\frac{\pi}{2\left(\frac{b}{H}\right)}\right)+\frac{1}{243} \tanh \left(\frac{3 \pi}{2\left(\frac{b}{H}\right)}\right)\right]\right\}} \\
& +\frac{1}{3 x^{+}}-2 \sum_{i=1}^{2} \frac{\left[3-\exp \left(-4 \alpha_{i}^{2} x^{+}\right)\right] \exp \left(-4 \alpha_{i}^{2} x^{+}\right)}{\alpha_{i}^{2} x^{+}}
\end{aligned}
$$

As the expression of Equation (11) demonstrated, $f R e_{D_{h}}$ represents the friction factor Reynolds number group in fully developed flow regime, which is merely the function of $b / H$

$$
f \operatorname{Re}_{D_{h}}=\frac{24}{\left(1+\left(\frac{b}{H}\right)\right)^{2}\left\{1-\frac{192\left(\frac{b}{H}\right)}{\pi^{5}}\left[\tanh \left(\frac{\pi}{2\left(\frac{b}{H}\right)}\right)+\frac{1}{243} \tanh \left(\frac{3 \pi}{2\left(\frac{b}{H}\right)}\right)\right]\right\}}
$$

The effectiveness of this fully developed model was validated with a great deal of available data. The experimental data of $0<H / s<1.4$ for pressure loss coefficient of the $90 \mathrm{deg}$ bend are obtained from Idelchik [40] and curve fitted as following.

$$
K_{\text {ort }}=3.64-9.15 \frac{H}{S}+10.87\left(\frac{H}{S}\right)^{2}-4.29\left(\frac{H}{S}\right)^{3}
$$


The pressure loss coefficient values of $90 \mathrm{deg}$ bend model can be calculated with the formula developed by Kondo et al. [41] when $H / s>1.4$

$$
K_{\mathrm{ort}}=0.5\left(\frac{1+V_{c h 2} / V_{c h 1}}{2}\right)^{2}
$$

Pressure drop form $\Delta P=K\left(\rho V^{2} / 2\right)$ is provided by Kays et al. [41], which is a function of free-flow area ratio for frontal area $\sigma=b /(b+t)$ to calculate the pressure losses between the inlet and exit. Contraction and expansion loss coefficients are obtained through curve fitting the data from Kays et al. [42]:

$$
\begin{gathered}
K_{c}=0.4\left(1-\sigma^{2}\right)+0.4 \\
K_{e}=\left(1-\sigma^{2}\right)-0.4 \sigma
\end{gathered}
$$

\section{Results and Discussion}

The number of grids has great influence on the time and precision of calculation. So we choose the number of grids considering both the precision requirements and computational time. Several appropriate grids that are suitable need to be designed. The number of grids was changed from approximately 33,655 to $3,876,420$ nodes, and the numerical simulation results are summarized in Figure 3.

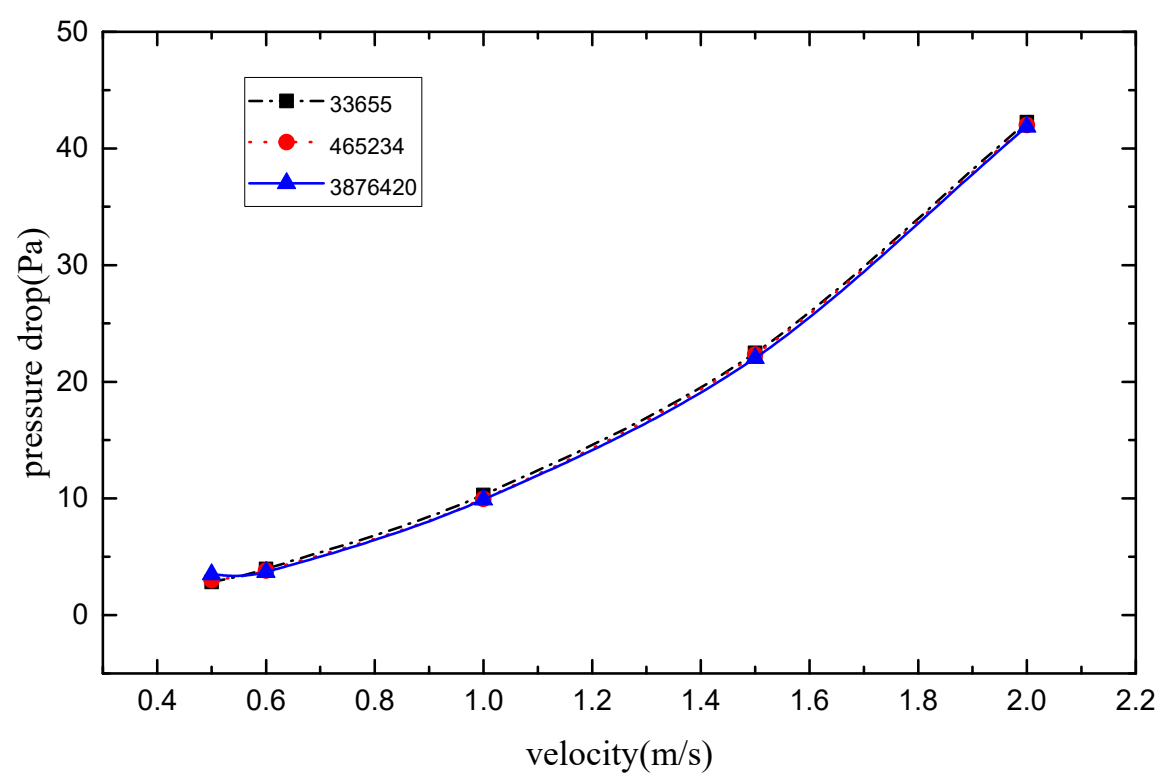

Figure 3. Grid independence verification results.

As shown in Figure 3, the result is almost independent of grid numbers and there is no significant change of the pressure drop results for different grids. The results of pressure drop for the plate fin heat sink with the number of grids of 33,655 has a relatively large deviation, and the maximum error is nearly $2 \%$. The results of pressure drop for the number of grids of 465,234 and 3,876,420 match quite well, the deviation is $1 \%$ which is relatively small. A grid of 465,234 nodes was chosen for the grid number of these numerical simulations considering computational time.

The experiments of pressure drop for plate fin heat sinks in laminar regime with different inlet widths subjected to impinging air flow were conducted by Duan and Muzychka [3]. Kim et al. [43] also made numerical simulations for pressure drop of plate fin heat sinks subjected to impinging air flow with the software ICEPAK produced by ANSYS Inc. Figure 4 compares the pressure drop for 
plate fin heat sink subjected to impinging air flow obtained in the present study with that conducted by Duan and Muzychka [3] and Kim et al. [43].

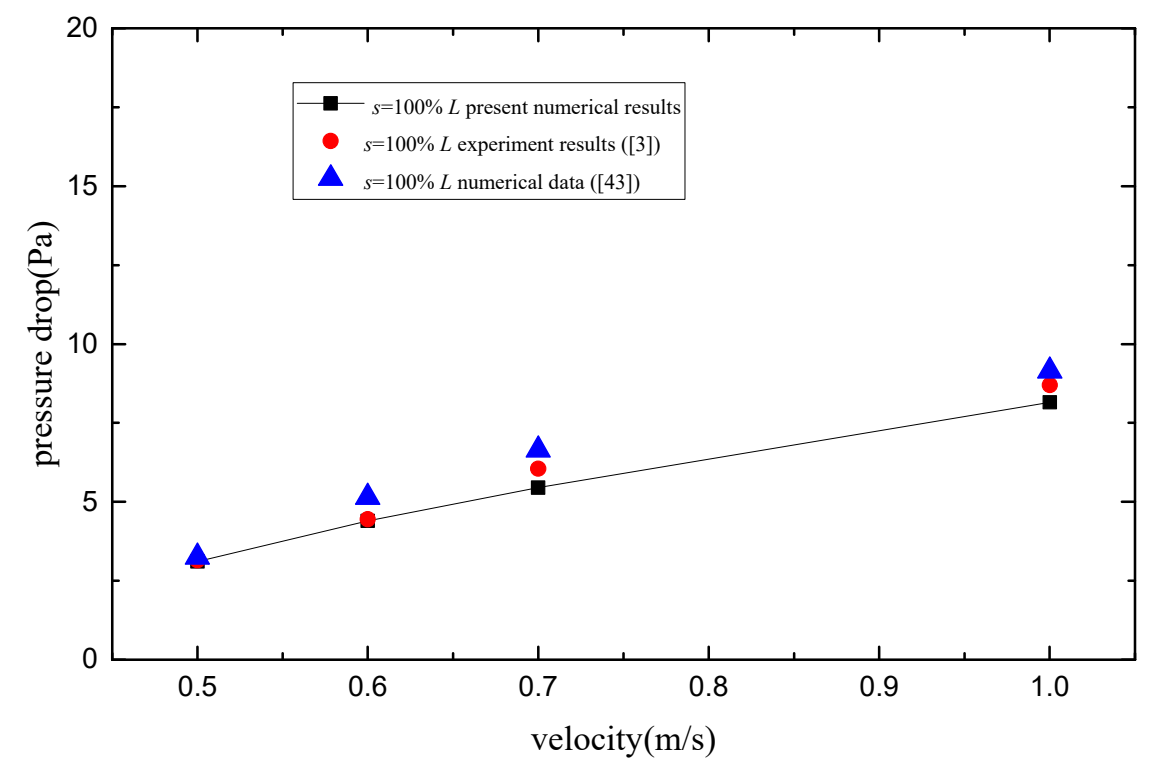

Figure 4. Comparison between the present results and experimental data by Duan and Muzychka [3] and simulation results by Kim et al. [43].

As shown in Figure 4, the pressure drop results obtained from the numerical simulation have a great consistency compared with those experimental data by Duan and Muzychka [3] and simulation results by Kim et al. [43]. Numerical simulation pressure drop results obtained by Kim et al. and the numerical simulations in the present study match well and the maximum error is within $15 \%$. The agreement of pressure drop results between present numerical simulations and the experimental data obtained by Duan and Muzychka [3] is quite satisfying in view of the uncertainties of pressure drop measurements. The effectiveness of the results obtained in the present paper was validated well.

In this paper, we also compare the pressure drop of number 1 plate fin heat sink for $s=10 \% \mathrm{~L}$ obtained from present numerical simulations with that obtained by experiments performed by Duan and Muzychka [3]. As shown in Figure 5, the error bars of 20\% is sketched in this picture and the present results agree well with the experimental results by Duan and Muzychka [3]. All the points lie within the range of experimental uncertainties and the maximum deviation is no more than $18 \%$ which is fairly fulfilling in consideration of uncertainty.

The results of pressure drop obtained from different research groups are shown in Figures 5 and 6 . The numerical simulations are performed with different channel widths for $b=1.44 \mathrm{~mm}$ and $b=2 \mathrm{~mm}$. The length and width used in this model are set to be $40 \mathrm{~mm}$ and $40 \mathrm{~mm}$ and the fin thickness is $0.5 \mathrm{~mm}$, which is consistent with the model geometry parameters of Kim et al. [6]. Figure 6 showed that the present results by numerical simulations are in great agreement with the experimental results obtained from Kim et al. [6]. As shown in Figure 6, the maximum deviation of the present results and the experimental results obtained by Kim et al. [6] is 19\%. The results acquired from numerical simulations are in agreement with experimental data provided by Kim et al. [6] in consideration of relatively large uncertainty for the experimental measurement. 


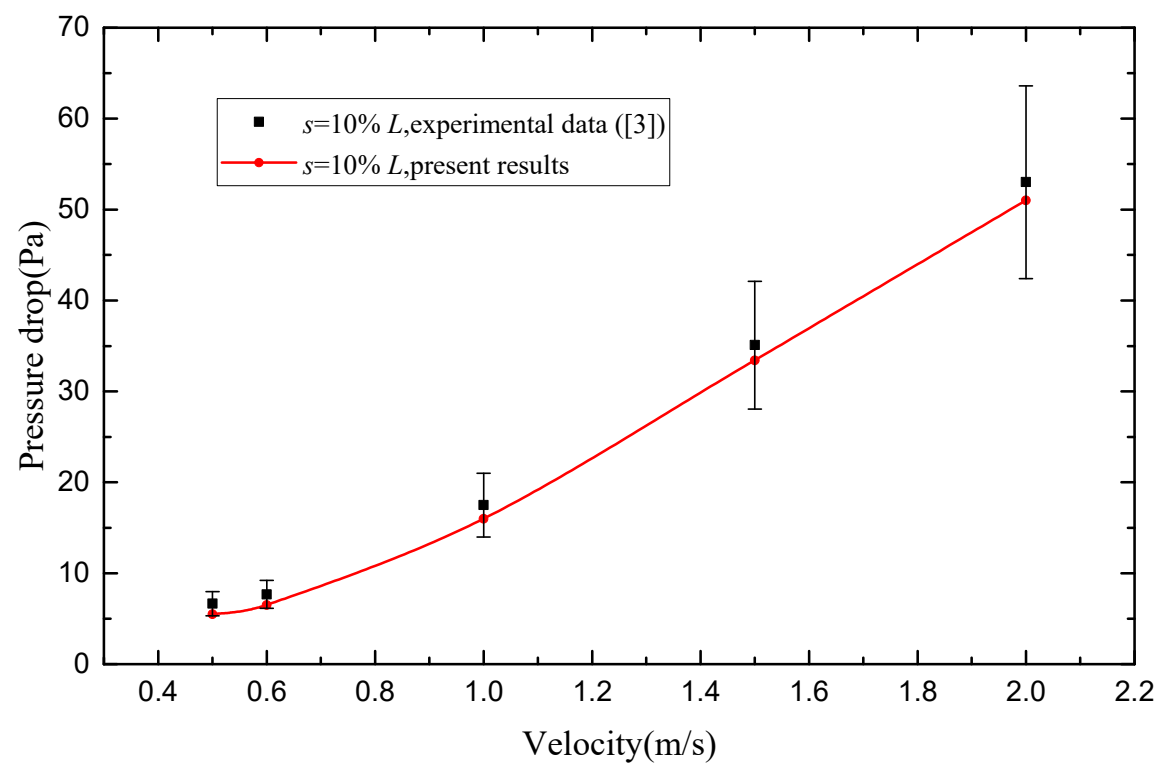

Figure 5. Comparison between the present numerical simulations and the experimental results obtained by Duan and Muzychka [3].

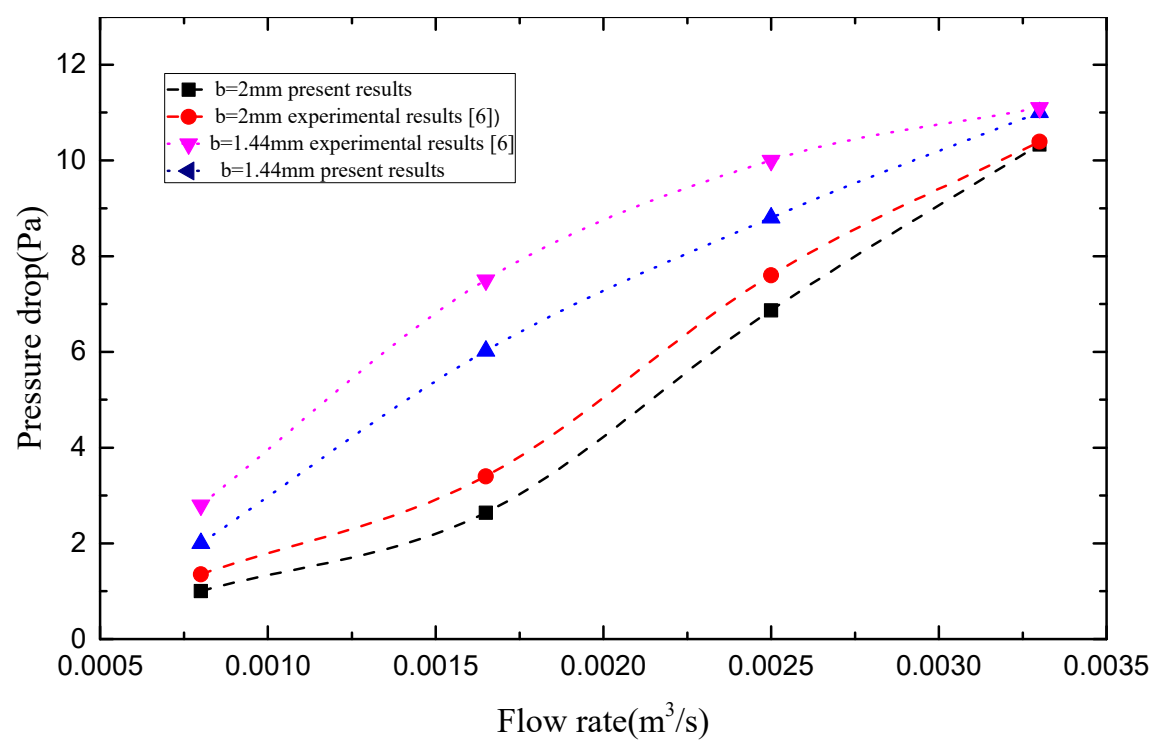

Figure 6. Comparison between the present numerical simulations and the experimental results obtained by Kim et al. [6].

This paper investigates the pressure drop of the plate fin heat sink subjected to impinging air flow with different inlet widths, fin heights, and the shapes of flow channels. The pressure drop values for the plate fin heat sink with different inlet velocities and construction parameters are obtained with numerical simulations in the current paper. There are eight different velocities applied to make the numerical simulations for the plate fin heat sink with impinging air flow, the corresponding velocity values are as follows: $0.3 \mathrm{~m} / \mathrm{s}, 0.5 \mathrm{~m} / \mathrm{s}, 0.6 \mathrm{~m} / \mathrm{s}, 0.7 \mathrm{~m} / \mathrm{s}, 0.8 \mathrm{~m} / \mathrm{s}, 1.0 \mathrm{~m} / \mathrm{s}, 1.5 \mathrm{~m} / \mathrm{s}$, and $2.0 \mathrm{~m} / \mathrm{s}$. The maximum value of Reynolds number is 1270 , which belongs to laminar flow regime.

Figure 7 shows the comparison of the streamlines in Y-Z symmetry plane for the plate fin heat sink subjected to impinging air flow without elliptic bottom profiles and that with elliptic bottom profiles in the condition of different velocities for $s=10 \% \mathrm{~L}$, and the comparison of velocity contours in $\mathrm{Y}-\mathrm{Z}$ symmetry plane for the plate fin heat sink with and without elliptic bottom profiles for $s=10 \% L$. The figures (left: $a, b, c)$ show the streamlines in Y-Z symmetry plane for the plate fin heat sink with elliptic 
bottom profiles on the bottom of the channels. As we can see, the flow impinging to the heat sink creates one vortex which occurs because of the jet impingement with the heat sink base. Relatively higher velocity results in a larger vortex for the heat sink with the same impinging inlet width. There are two vortices in $\mathrm{Y}-\mathrm{Z}$ symmetry plane when the velocity increases to $2.0 \mathrm{~m} / \mathrm{s}$. For higher velocity, the generated vortex is strengthened because of the decreasing viscous force. As the elliptic bottom profiles are added to the channels, the jet vortex becomes smaller. This approach leads to smooth flow in the channels and the vortex because of impingement shifts to the direction of the outlet, away from the symmetry plane.

Figures 8-11 compare the pressure drop for the number 1 to number 4 plate fin heat sinks subjected to impinging air flow for different inlet widths obtained from the present model and the numerical simulation results with the experimental data acquired by Duan and Muzychka [3]. Results for the pressure drop obtained from the experiments, the present model and the present numerical simulations match quite well and the maximum error is no more than $25 \%$. The pressure drop increases with a decrease in impingement inlet width for the same flow rate. The pressure drop of the plate fin heat sink under impinging air flow increases with the inlet velocity especially obvious for larger inlet width. The change rate of pressure drop increases with the decreasing inlet width. As the inlet width increases, the pressure drop in the Z-direction slightly decreases, which is caused by the decrease in the averaged velocity. In the same plate fin heat sink flow path, increasing the velocity directly leads to the collision between the fluid molecules, and the fluid molecules exchange momentum with each other to generate more energy loss, and the quantity of surrounding fluid induced by the jet impingement increases with the increased speed. The motion causes a greater viscous force and more intense shear stress, and momentum exchange occurs between the fluids at the boundary at the two sides of the jet impingement, which in turn causes an increase in maximum pressure drop.

Figure 12 shows the comparison of the pressure drop for plate fin heat sinks with elliptic bottom profiles and without elliptic bottom profiles on the bottom of the channels. It can be observed that the pressure drop for the plate fin heat sink without elliptic bottom profiles is larger than that for plate fin heat sink with elliptic bottom profiles especially for the smaller inlet width. The differences of the pressure drop for the heat sink with or without elliptic bottom profiles on the bottom of the channels are not very obvious for the larger inlet width. The contact resistance is decreased with the presence of elliptic bottom profiles due to the additional substrate materials adding at the bottom of fins, which makes channels smoother. When modifying rectangular channels into channels with elliptic bottom profiles, the contact area between the cooling fluid and heat sink is slightly increased. The friction between the cooling fluid and solid and the flow resistance losses will decrease significantly as a result. The perpendicular angle bend flow in a channel with fillet profile becomes significantly smoother as well. It is worth mentioning that Figure 12 expresses the comparison of the pressure drop for the plate fin heat sink subject to impinging air flow without elliptic bottom profiles and that with elliptic bottom profiles. This modification may shed some light on a better design for heat sinks.

Figure 13 shows the comparison of the velocity distributions at the plane of half fin height $\mathrm{Z}=13.25 \mathrm{~mm}$ for the plate fin heat sink without elliptic bottom profiles and that with elliptic bottom profiles for $s=10 \% \mathrm{~L}$. The results demonstrate a striking trend: the mean velocity is smaller for the channels with elliptic bottom profiles as compared to channels without elliptic bottom profiles, regardless of the channel width. The distribution of velocity for the plate fin heat sink with elliptic bottom profiles is more uniform than that without elliptic bottom profiles. There are three peak velocities at the condition of $v=0.5 \mathrm{~m} / \mathrm{s}$ for the plate fin heat sink without elliptic bottom profiles. The change from a rectangular channel to a fillet profile channel reduces the friction and the contact area between the fluid and the fin due to the addition of the fillet profile, which will lead to a smaller pressure drop. 


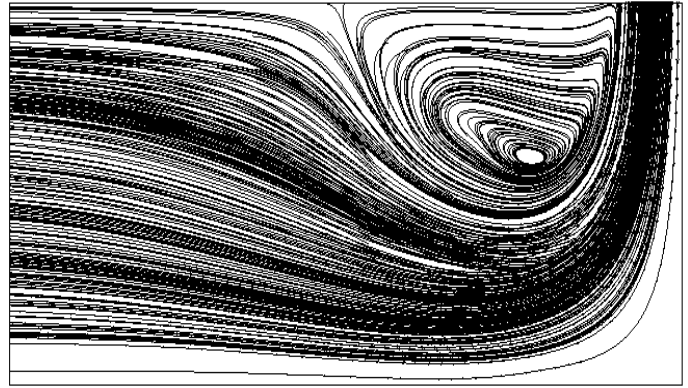

(a) $v=0.5 \mathrm{~m} / \mathrm{s}$

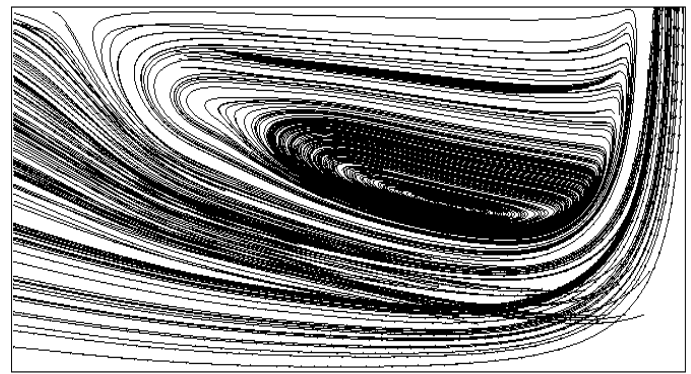

(b) $v=1.0 \mathrm{~m} / \mathrm{s}$

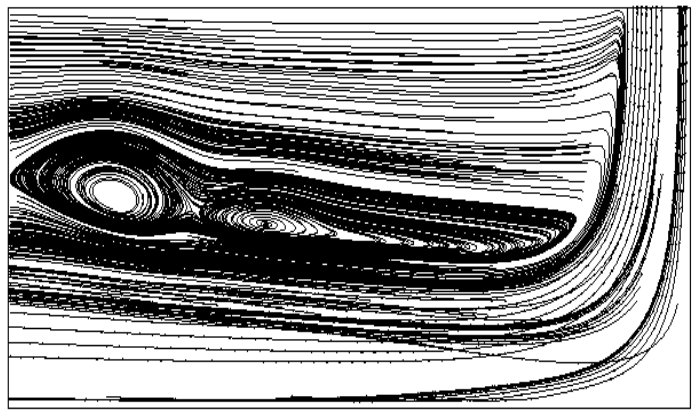

(c) $v=2.0 \mathrm{~m} / \mathrm{s}$

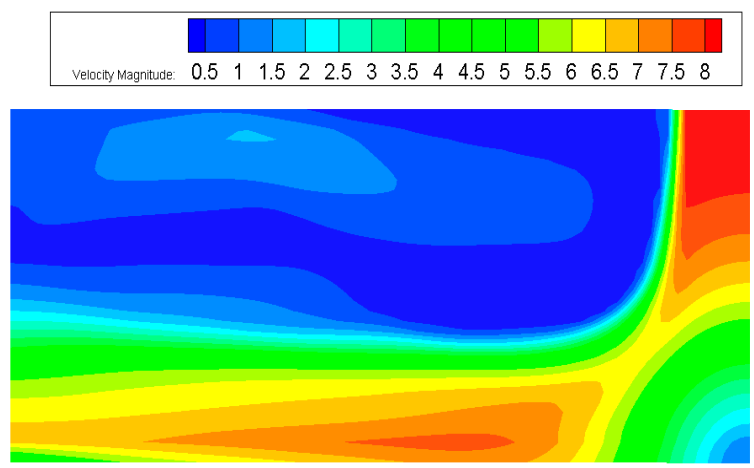

(d) $v=2.0 \mathrm{~m} / \mathrm{s}$

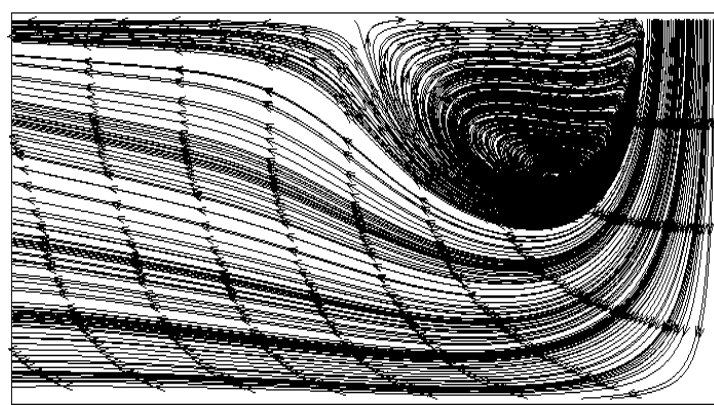

(e) $v=0.5 \mathrm{~m} / \mathrm{s}$

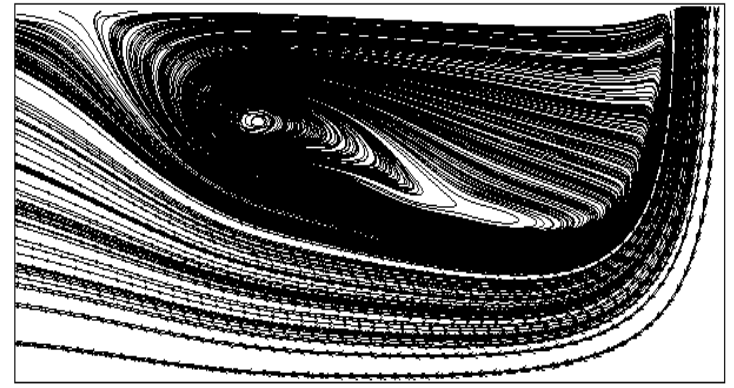

(f) $v=1.0 \mathrm{~m} / \mathrm{s}$

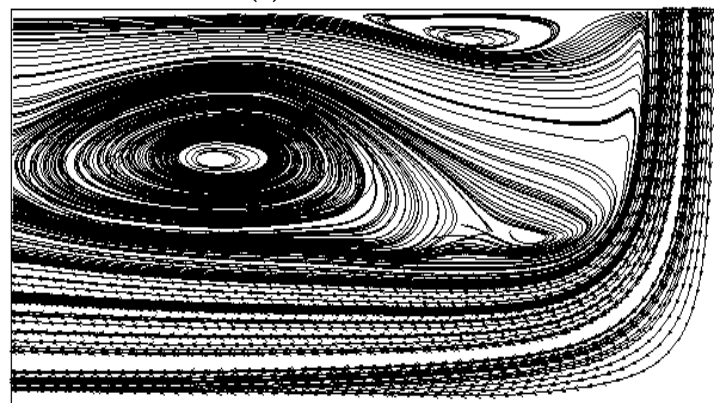

(g) $v=2.0 \mathrm{~m} / \mathrm{s}$
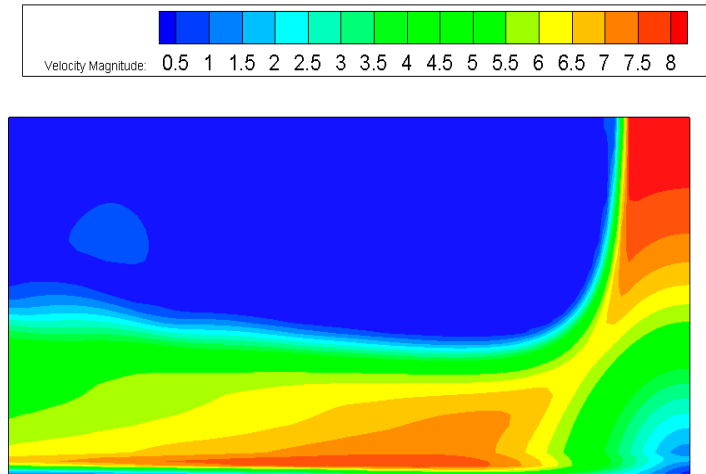

(h) $v=2.0 \mathrm{~m} / \mathrm{s}$

Figure 7. Streamlines in Y-Z symmetry plane for the plate fin heat sink with (left: $(\mathbf{a}-\mathbf{c}))$ and without (right: (e-g)) elliptic bottom profiles in the condition of $s=10 \% L$ for different velocities $v=0.5,1.0$, and $2.0 \mathrm{~m} / \mathrm{s}$; velocity contours in Y-Z symmetry plane for the plate fin heat sink with (left: (d)) and without (right: (h)) elliptic bottom profiles in the condition of $s=10 \% L$ for $v=2.0 \mathrm{~m} / \mathrm{s}$. 


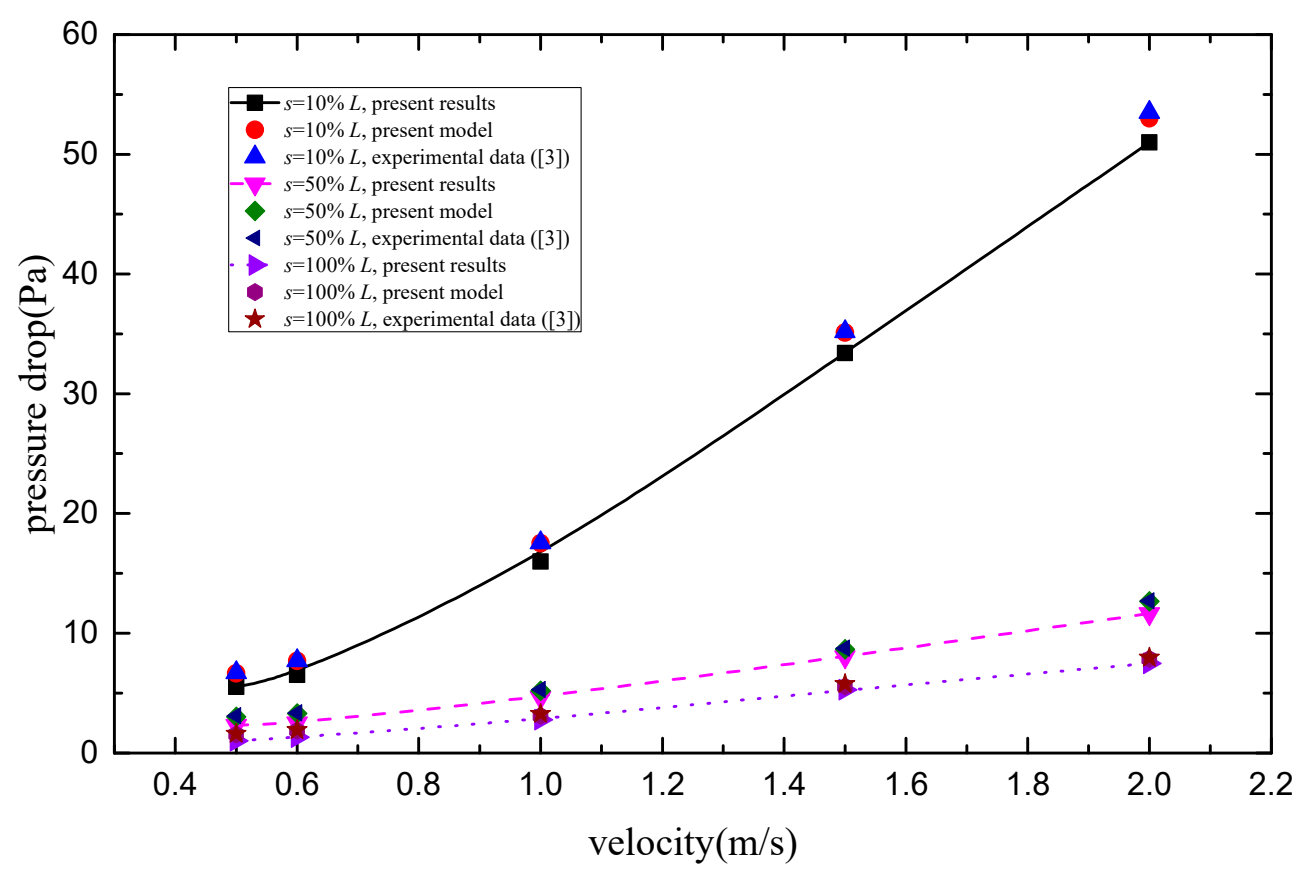

Figure 8. Comparisons of the pressure drop for the \#1 plate fin heat sink.

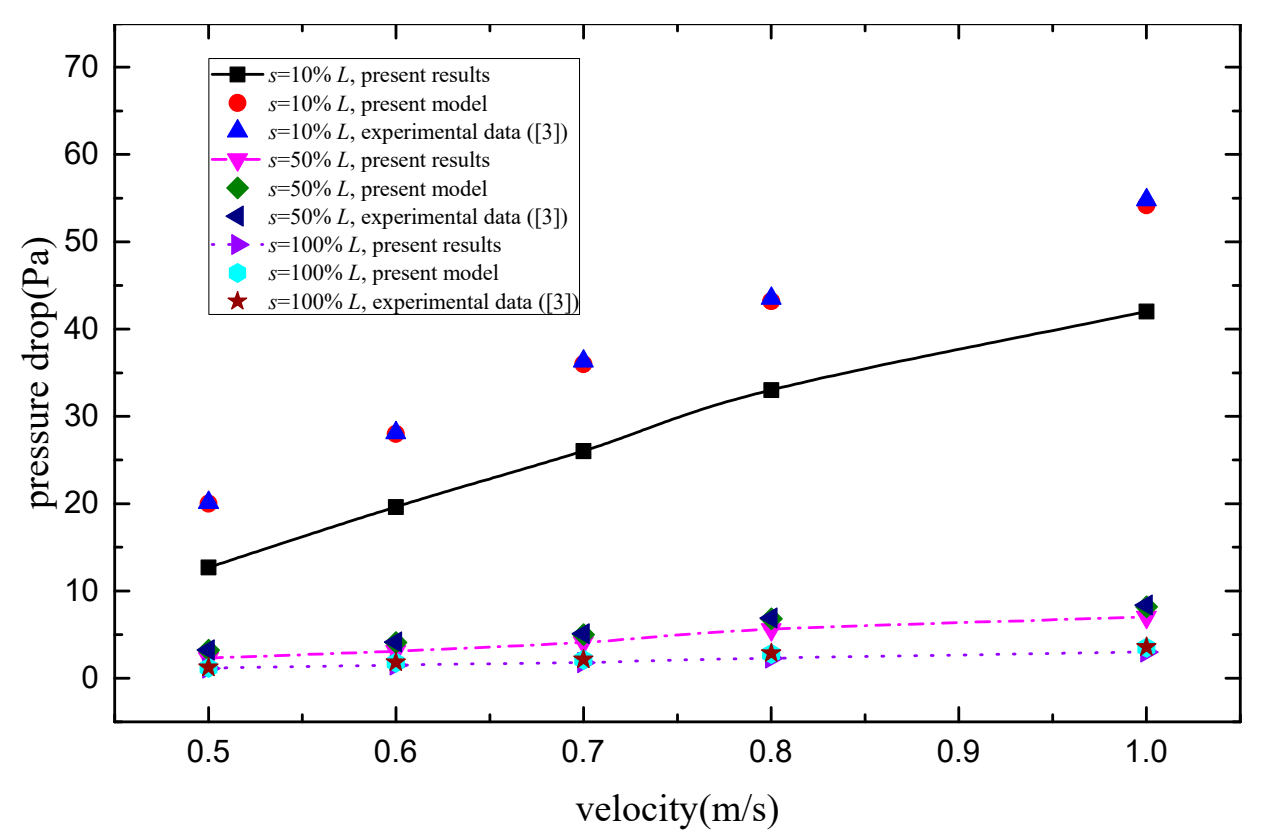

Figure 9. Comparisons of the pressure drop for the \#2 plate fin heat sink. 


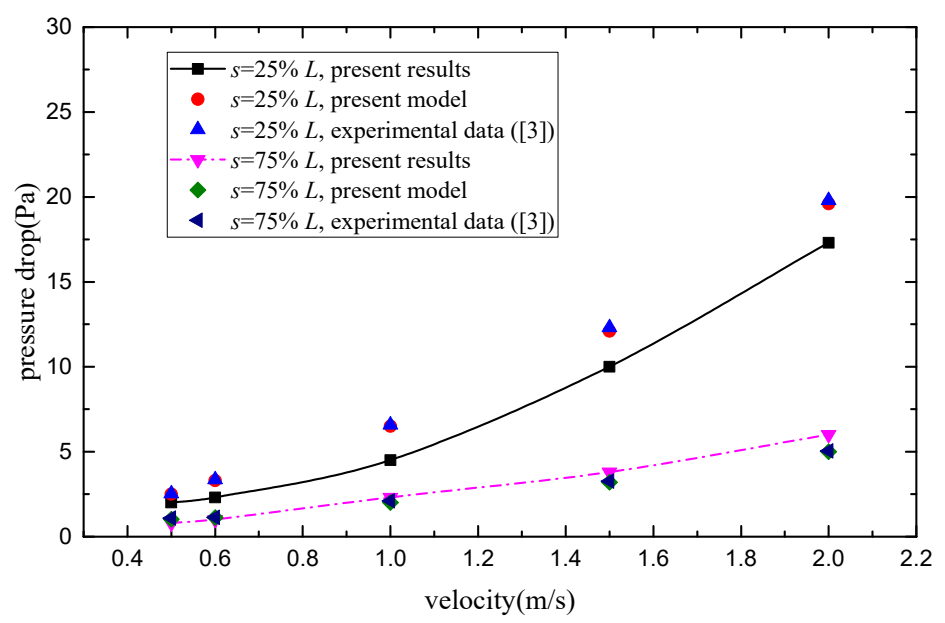

Figure 10. Comparisons of the pressure drop for the \#3 plate fin heat sink.

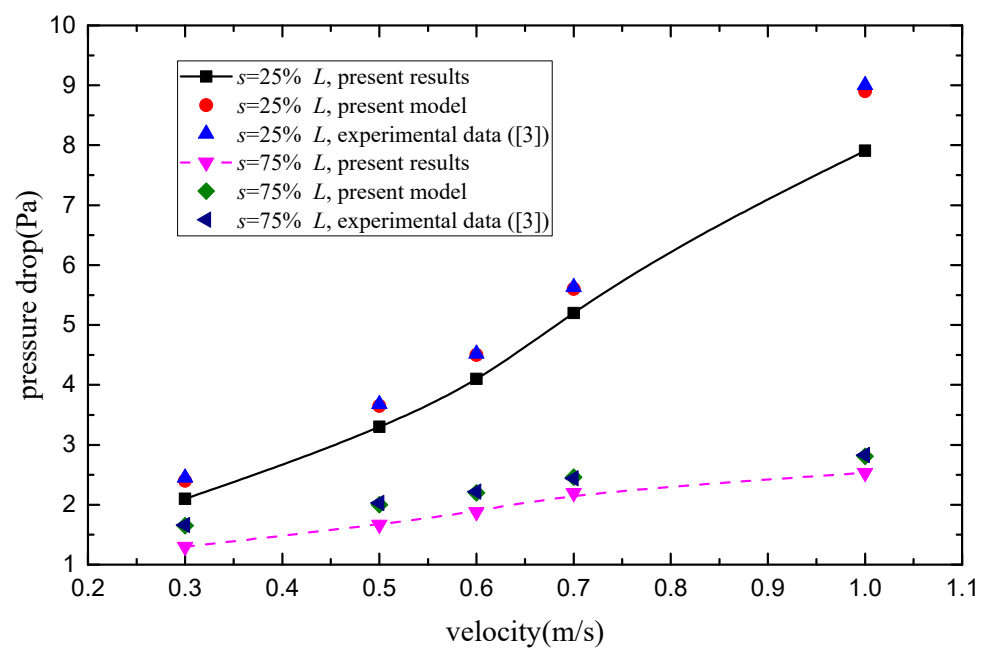

Figure 11. Comparisons of the pressure drop for the \#4 plate fin heat sink.

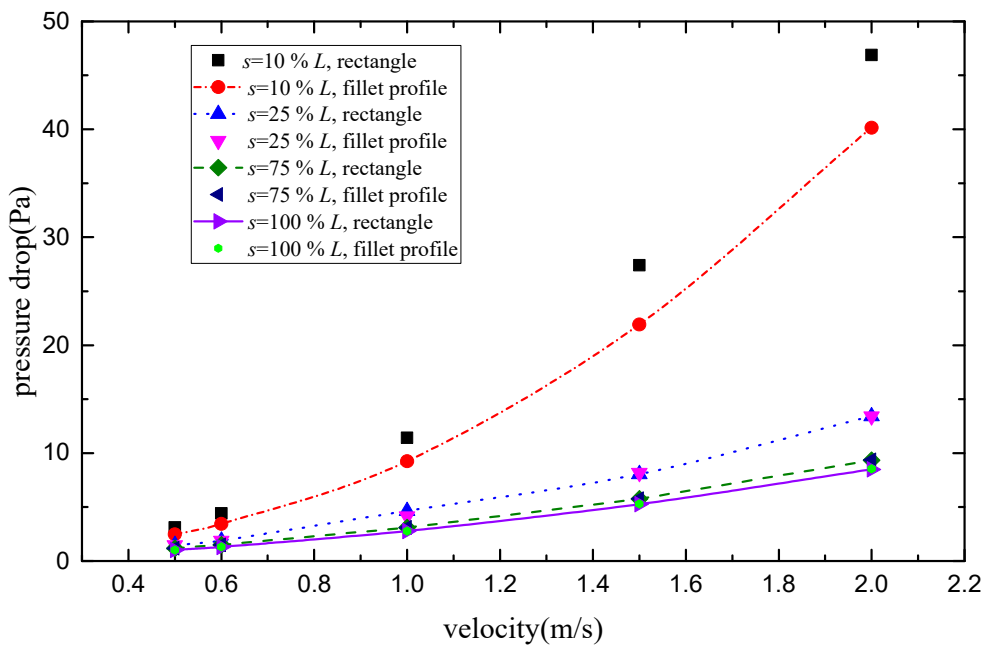

Figure 12. Comparison of the pressure drop of plate fin heat sink with elliptic bottom profiles and without elliptic bottom profiles on the bottom of the channels. 

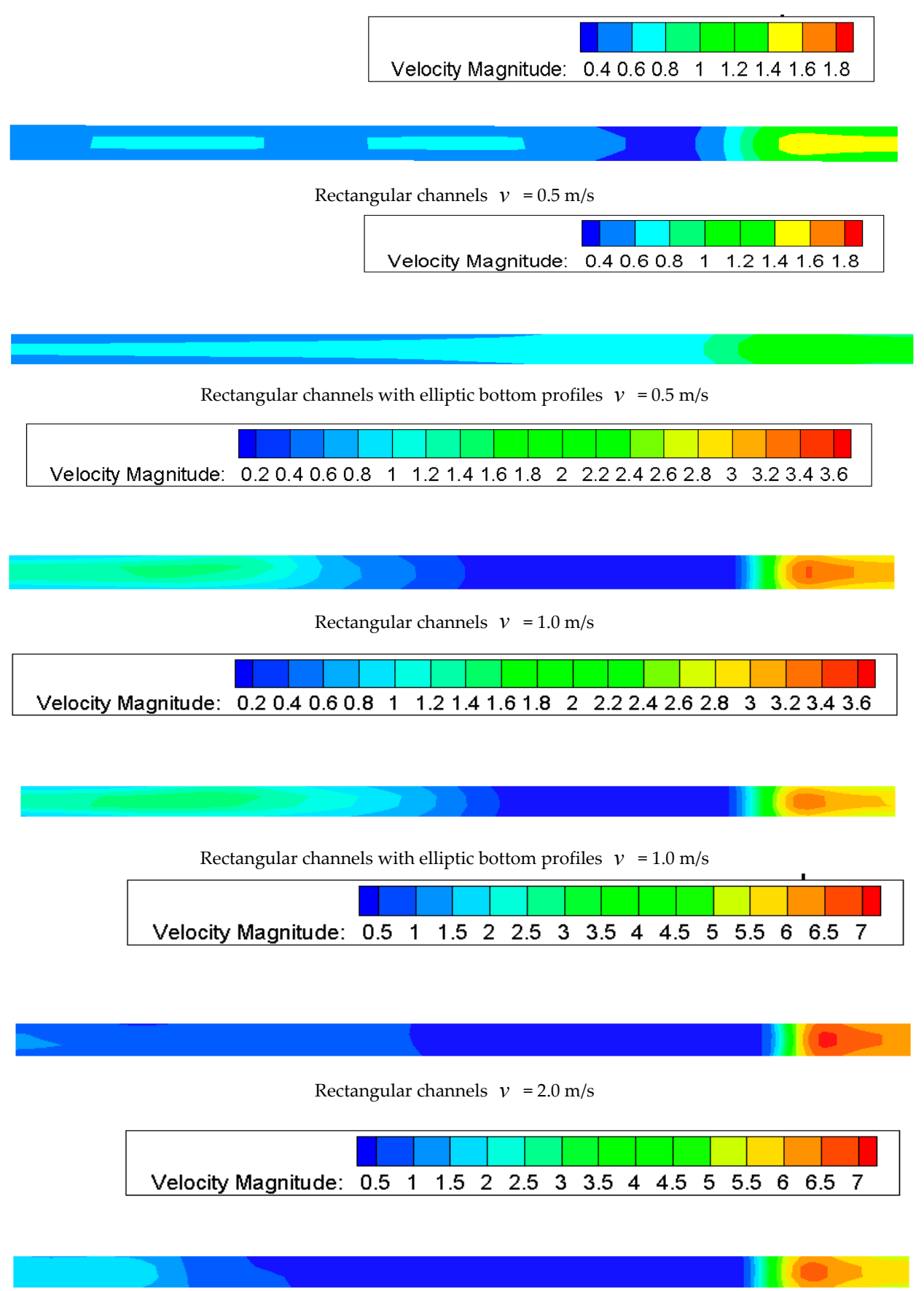

Rectangular channels with elliptic bottom profiles $v=2.0 \mathrm{~m} / \mathrm{s}$

Figure 13. Comparisons of the velocity distributions at the plane of half fin height $Z=13.25 \mathrm{~mm}$ for the plate fin heat sinks \#1 and \#5.

\section{Conclusions}

This paper investigated the pressure drop of a plate fin heat sink subjected to an impinging flow with elliptic bottom profiles. Comprehensive evaluation for fluid flow performance was studied as well. Investigations were performed for variable velocities, fin heights, fin spacings, and inlet channel widths. Distribution of streamlines and velocities of different shaped heat sink were plotted in this work. Results for the pressure drop obtained from the numerical simulations and the experiments performed by Duan and Muzychka [3] fit well and the maximum error is no more than $25 \%$, which is fairly fulfilling in consideration of the experimental uncertainty. The flow situation at the entrance 
of the plate fin heat sink is extremely complicated, as well as the right-angled bends. Based on the fundamental laminar developing continuum flow theory in the entrance of ducts, an improved model which is very concise and nice for quick real world approximations was proposed. When comparing the results for the pressure drop obtained from the numerical calculations and the proposed improved model, the maximum deviation is no more than $15 \%$. It is pronounced that plate fin heat sinks with elliptic bottom profiles possess lower pressure drop and more uniform velocity distribution than that without elliptic bottom profiles with the same inlet widths and velocities. The change from a rectangular channel to an elliptic bottom profile channel reduces the friction and the contact area between the fluid and the fin due to the addition of the elliptic bottom, which leads to a smaller pressure drop. Larger inlet width leads to lower pressure drop regardless of the velocity.

Therefore, the developed model may be used to predict the pressure drop of fluid flow in impinging plate fin heat sinks for minimizing the effort and expense of experiments, especially in the design and optimization of microchannel plate fin heat sinks for engineers and scientists.

Author Contributions: Conceptualization, Z.D. and X.L.; methodology, Z.D.; software, L.S. and H.M.; validation, Z.D. and X.L.; writing-review and editing, Z.D. and X.L. All authors discussed the results. All authors have read and agreed to the published version of the manuscript.

Funding: This work is supported by the National Natural Science Foundation of China under No. 51576013 and the National Key R\&D Program of China under No. 2017YFB0102101.

Acknowledgments: The authors acknowledge Michael Yovanovich and Yuri Muzychka, who introduced the first author to the development of compact models of pressure drop for plate fin heat sinks.

Conflicts of Interest: The authors declare no conflict of interest.

\section{Abbreviations}

\section{Nomenclature}

$b$

$D_{h}$

$f, f_{\text {app }}$

$H$

$K_{c}, K_{e}$

$K_{\text {ort }}$

$K n^{*}$

L

$L_{e f f}$

$N_{f}$

$\Delta P$

$\operatorname{Re}_{D_{h}}$

$s$

$t$

$t_{b}$

$u v w$

W

$x^{+}$

Greek symbols

$\alpha_{i}$

$\mu$

$\rho$

$\sigma$

Subscripts

1

2

ch fin spacing, $\mathrm{m}$

hydraulic diameter, $\mathrm{m}$

friction factor and apparent friction factor, respectively

fin height, $m$

contraction and expansion loss coefficient, respectively

loss coefficient due to $90 \mathrm{deg}$ bend in airflow

modified Knudsen number

length of heat sink base, $\mathrm{m}$

effective length, $\mathrm{m}$

number of fins

pressure drop, $\mathrm{Pa}$

channel Reynolds number, $=D_{h} V_{c h} / v$

impingement inlet width, $\mathrm{m}$

fin thickness, $\mathrm{m}$

base plate thickness, $\mathrm{m}$

velocity components of $X, Y, Z$ coordinates

width of heat sink base, $m$

dimensionless flow length

eigenvalue

dynamic viscosity, $\mathrm{N} \cdot \mathrm{s} / \mathrm{m}^{2}$

density of air, $\mathrm{kg} / \mathrm{m}^{3}$

fraction of frontal free flow area

based upon vertical channel

based upon horizontal channel

channel 


\section{References}

1. Jang, S.P.; Kim, S.J. Fluid flow and thermal characteristics of a microchannel heat sink subject to an impinging air jet. Trans. ASME J. Heat Transf. 2005, 127, 770-779. [CrossRef]

2. Biber, C.R. Pressure drop and heat transfer in an isothermal channel with impinging flow. IEEE Trans. Compon. Packag. Manuf. Technol. Part A 1997, 20, 458-462. [CrossRef]

3. Duan, Z.P.; Muzychka, Y.S. Pressure drop of impingement air cooled plate fin heat sinks. Trans. ASME J. Electron. Packag. 2007, 129, 190-194. [CrossRef]

4. Ma, H.; Duan, Z.P.; Su, L.B.; Ning, X.R.; Bai, J.; Lv, X.H. Fluid flow and entropy generation analysis of $\mathrm{Al}_{2} \mathrm{O}_{3}$-Water nanofluid in microchannel plate fin heat sinks. Entropy 2019, 21, 739. [CrossRef]

5. Ma, N.Y.; Duan, Z.P.; Ma, H.; Su, L.B.; Liang, P.; Ning, X.R. Lattice Boltzmann simulation of the hydronamic entrance region of rectangular microchannels in the slip regime. Micromachines 2018, 9, 87. [CrossRef]

6. Kim, D.K.; Kim, S.J.; Bae, J.K. Comparison of thermal performances of plate-fin and pin-fin heat sinks subject to an impinging flow. Int. J. Heat Mass Transf. 2009, 52, 3510-3517. [CrossRef]

7. Yang, Y.T.; Lin, S.C.; Wang, Y.H.; Hsu, J.C. Numerical simulation and optimization of impingement cooling for rotating and stationary pin-fin heat sinks. Int. J. Heat Fluid Flow 2013, 44, 383-393. [CrossRef]

8. Wong, K.C.; Indran, S. Impingement heat transfer of a plate fin heat sink with fillet profile. Int. J. Heat Mass Transf. 2013, 65, 1-9. [CrossRef]

9. Do, K.H.; Kim, T.H.; Kim, S.J. Analytical and experimental investigations on fluid flow and thermal characteristics of a plate-fin heat sink subject to a uniformly impinging jet. Int. J. Heat Mass Transf. 2010, 53, 2318-2323. [CrossRef]

10. Ndao, S.; Peles, Y.; Jensen, M.K. Effects of pin fin shape and configuration on the single-phase heat transfer characteristics of jet impingement on micro pin fins. Int. J. Heat Mass Transf. 2014, 70, 856-863. [CrossRef]

11. Tang, Z.G.; Liu, Q.Q.; Li, H.; Min, X.T. Numerical simulation of heat transfer characteristics of jet impingement with a novel single cone heat sink. Appl. Therm. Eng. 2017, 8, 840-852. [CrossRef]

12. Li, X.C. Conjugate heat transfer of jet impingement on short fins with different shapes. In Proceedings of the 11th Intersociety Conference on Thermal and Thermomechanical Phenomena in Electronic Systems, Orlando, FL, USA, 28-31 May 2008; pp. 49-56.

13. Li, H.Y.; Chen, K.Y.; Chiang, M.H. Thermal-fluid characteristics of plate-fin heat sinks cooled by impingement jet. Energy Convers. Manag. 2009, 50, 2738-2746. [CrossRef]

14. Khattak, Z.; Ali, H.M. Air cooled heat sink geometries subjected to forced flow: A critical review. Int. J. Heat Mass Transf. 2019, 130, 141-161. [CrossRef]

15. Chang, Y.W.; Chang, C.C.; Ke, M.T. Thermoelectric air-cooling module for electronic devices. Appl. Therm. Eng. 2009, 29, 2731-2737. [CrossRef]

16. Wang, C.C.; Hung, C.I.; Chen, W.H. Design of heat sink for improving the performance of thermoelectric generator using two-stage optimization. Energy 2012, 39, 236-245. [CrossRef]

17. Saraireh, M. Computational fluid dynamics simulation of plate fin and circular pin fin heat sinks. Jordan J. Mech. Ind. Eng. 2016, 10, 99-104.

18. Hussain, A.A.; Freegah, B.; Khalaf, B.S.; Towsyfyan, H. Numerical investigation of heat transfer enhancement in plate-fin heat sinks: Effect of flow direction and fillet profile. Case Stud. Therm. Eng. 2019, 13, 100388. [CrossRef]

19. Feng, S.S.; Kuang, J.J.; Lu, T.J. Heat transfer and pressure drop characteristics of finned metal foam heat sinks under uniform impinging flow. Trans. ASME J. Electron. Packag. 2015, 137, 14-27. [CrossRef]

20. Hadad, Y.; Ramakrishnan, B.; Alkharabsheh, S.; Chiarot, P.R.; Sammakia, B. Numerical modeling and optimization of a V-groove warm water cold-plate. In Proceedings of the 33rd Thermal Measurement, Modeling \& Management Symposium (SEMI-THERM), San Jose, CA, USA, 13-17 March 2017.

21. Kaloudis, E.; Nikas, K.S. A parametric numerical study of fluid flow and heat transfer in a computer chassis. Int. Rev. Mech. Eng. 2015, 9, 242-250. [CrossRef]

22. Prstic, S.; Bar-Cohen, A. "Heat shield"-An enhancement device for an unshrouded forced convection heat sink. J. Electron. Packag. 2006, 128, 172-176. [CrossRef]

23. Mesalhy, O.M.; El-Sayed, M.M. Thermal performance of plate fin heat sink cooled by air slot impinging jet with different cross-sectional area. Heat Mass Transf. 2015, 51, 889-899. [CrossRef] 
24. Chen, W.H.; Huang, S.R.; Lin, Y.L. Performance analysis and optimum operation of a thermoelectric generator by Taguchi method. Appl. Energy 2015, 158, 44-54. [CrossRef]

25. Rezania, A.; Rosendahl, L.A. A comparison of micro-structured flat-plate and cross-cut heat sinks for thermoelectric generation application. Energy Convers. Manag. 2015, 101, 730-737. [CrossRef]

26. Leng, C.; Wang, X.D.; Wang, T.H.; Yan, W.M. Optimization of thermal resistance and bottom wall temperature uniformity for double-layered microchannel heat sink. Energy Convers. Manag. 2015, 93, 141-150. [CrossRef]

27. Naphon, P.; Wiriyasart, S.; Arisariyawong, T.; Nakharintr, L. ANN, numerical and experimental analysis on the jet impingement nanofluids flow and heat transfer characteristics in the micro-channel heat sink. Int. J. Heat Mass Transf. 2019, 131, 329-340. [CrossRef]

28. Huang, C.H.; Chen, Y.H. An optimal design problem in determining non-uniform fin heights and widths for an impingement heat sink module. Appl. Therm. Eng. 2014, 63, 481-494. [CrossRef]

29. Chen, G.J.; Liu, Y.Y.; Rao, Y.; He, J.H.; Qu, Y.F. Numerical investigation on conjugate heat transfer of impingement/effusion double-wall cooling with different crossflow schemes. Appl. Therm. Eng. 2019, 155, 515-524. [CrossRef]

30. Liang, C.H.; Tong, X.M.; Lei, T.Y.; Li, Z.X.; Wu, G.S. Optimal design of an air-to-air heat exchanger with cross-corrugated triangular ducts by using a particle swarm optimization algorithm. Appl. Sci. 2017, 7, 554. [CrossRef]

31. Ling, Z.Y.; He, Z.B.; Xu, T.; Fang, X.M.; Gao, X.N.; Zhang, Z.G. Experimental and numerical investigation on non-Newtonian nanofluids flowing in shell side of helical baffled heat exchanger combined with elliptic tubes. Appl. Sci. 2017, 7, 48. [CrossRef]

32. Chang, S.Y.; Chen, J.C.; Shi, L. Using thermal shock to inhibit biofilm formation in the treated sewage source heat pump systems. Appl. Sci. 2017, 7, 343. [CrossRef]

33. Biskeborn, R.G.; Horvath, J.L.; Hultmark, E.B. Integral cap heat sink assembly for IBM 4381 processor. In Proceedings of the International Electronics Packaging Conference, Baltimore, MD, USA, 14-18 October 1984; pp. 468-474.

34. Hilbert, C.; Sommerfeldt, S.; Gupta, O.; Herrell, D.J. High performance micro-channel air cooling. In Proceedings of the 6th Annual IEEE Semiconductor Thermal and Temperature Measurement Symposium, Scottsdale, AZ, USA, 6-8 February 1990; pp. 108-113.

35. Duan, Z.P.; Liang, P.; Ma, H.; Ma, N.Y. Numerical simulation of pressure drop for three-dimensional rectangular microchannels. Eng. Comput. 2018, 35, 2234-2254. [CrossRef]

36. Duan, Z.P.; He, B.S. Extended Reynolds analogy for slip and transition flow heat transfer in microchannels and nanochannels. Int. Commun. Heat Mass Transf. 2014, 56, 25-30. [CrossRef]

37. Duan, Z.P.; He, B.S.; Duan, Y.Y. Sphere drag and heat transfer. Sci. Rep. 2015, 5, 12304. [CrossRef] [PubMed]

38. Duan, Z.P.; Ma, H.; He, B.S.; Su, L.B. Pressure drop of microchannel plate fin heat sinks. Micromachines 2019, 10, 80. [CrossRef] [PubMed]

39. Duan, Z.P. Pressure drop for subsonic gas flow in microchannels and nanochannels. Nanoscale Microscale Thermophys. Eng. 2012, 16, 117-132. [CrossRef]

40. Idelchik, I.E. Handbook of Hydraulic Resistance, 3rd ed.; CRC: Boca Raton, FL, USA, 1993.

41. Kondo, Y.; Matsuhima, H. Prediction algorithm of pressure drop for impingement cooling of heat sinks with longitudinal fins. Trans. Jpn. Soc. Mech. Eng. Ser. B 1995, 244, 315-327.

42. Kays, W.M.; London, A.L. Compact Heat Exchangers, 3rd ed.; McGraw-Hill: New York, NY, USA, 1984.

43. Kim, T.H.; Do, K.H.; Kim, S.J. Closed-form correlations of pressure drop and thermal resistance for a plate fin heat sink with uniform air jet impingement. Energy Convers. Manag. 2017, 136, 340-349. [CrossRef]

(C) 2019 by the authors. Licensee MDPI, Basel, Switzerland. This article is an open access article distributed under the terms and conditions of the Creative Commons Attribution (CC BY) license (http://creativecommons.org/licenses/by/4.0/). 